\title{
Materials Research Science and Engineering Centers (MRSECs) provide collaboration and diversity in research and outreach
}

$\mathrm{T}_{\mathrm{s}}$ he National Science Foundation (NSF) awards funding to Materials Research Science and Engineering Centers (MRSECs) ${ }^{1}$ for transdisciplinary work that covers all areas of materials science and helps foster collaborations on national and international levels.

During the course of the six-year grant, MRSECs tackle innovative, challenging research questions that are too large and complex for a single primary investigator (PI) or small group of researchers to answer. The research funding is interdisciplinary - across departments and colleges - and helps to break down institutional silos. These centers serve as hubs of collaboration and support some of the world's best materials research and education initiatives.

There are currently 20 MRSECs that involve more than 2200 participants ranging from faculty and postdocs to graduate students, undergraduate students, and technicians. Of the more recent MRSEC awards, three are to new institutions: The University of Texas at Austin, the University of Illinois at Urbana-Champaign, and the University of Washington.

In addition to primary research, MRSEC members are also charged with volunteering for education and outreach efforts, where they can engage with and positively affect target audiences of all ages, with the goal of increasing participation in science, technology, engineering, and mathematics (STEM) fields and building the next-generation STEM workforce. This center-level investment in outreach and human resource development is an important part of the MRSEC structure and a key element in reaching overall impact goals. Therefore, while the grant is fundamentally a research award, proposed activities that extend beyond the laboratory are critically important.

"The education, outreach, diversity, and other broader impact efforts in a MRSEC grant have to evolve as well as the research," said Kristin Dreyer, MRSEC Program

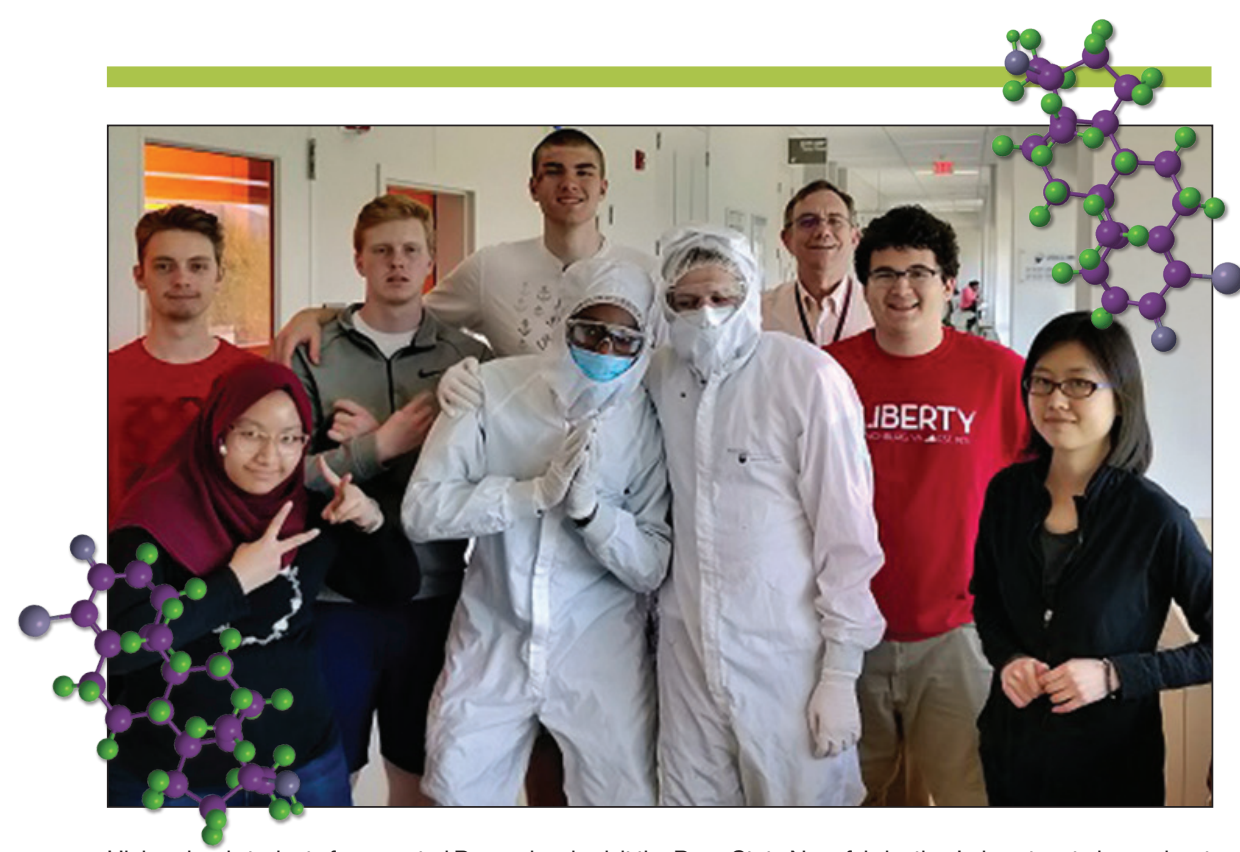

High-school students from central Pennsylvania visit the Penn State Nanofabrication Laboratory to learn about materials science from graduate student, Yixian Chen. Credit: Penn State Center for Nanoscale Science.
Director for Education and Outreach at the Center for Nanoscale Science ${ }^{2}$ at The Pennsylvania State University (Penn State). "In other words, because MRSECs are large, the expectation for its proposed education and outreach strategy is that it should be ambitious, exciting, and challenging to accomplish," added Dreyer.

Penn State's Center for Nanoscale Science involves approximately 45 students and postdoctoral fellows and 40 faculty members from seven academic departments. The Center's activities are currently organized around four interdisciplinary research groups (IRGs) that provide an umbrella-like infrastructure at the university, and three Outreach Teams that each include representatives from all IRGs. The education and outreach structure builds community across the entire Center.

"Our education and outreach structure creates bridges between IRGs, as well as between researchers in the materials community," said Dreyer. "The entire community is invited to volunteer and participate in our programs. Outreach activities are not only designed for the target audience. They are intentionally structured to build additional professional and interpersonal skills in the volunteers that are essential to future employment. In addition to more traditional professional development activities, we include a focus in efforts such as creating and presenting science demonstrations and lessons; giving facilities tours; organizing and implementing recruitment and retention activities; sharing with teachers; and mentoring undergraduates," said Dreyer. "Because we do so, we commonly receive requests from student organizations and other people who want to join us and get involved."

The Penn State Chapter of the Materials Research Society (MRS) is no exception. In the past year, the Chapter has actively collaborated by contributing to MRSEC-sponsored activities 
that empower youth and share the joys of materials science. Chapter members taught materials science fundamentals to college-bound high-school students who are blind or visually impaired, through engaging demonstrations at the STEM Extension Weekend of Summer Academy. ${ }^{3}$ In doing so, attendees received a firsthand taste of materials science and the knowledge of the various avenues that are open to them in college. During the "Kids Day" portion of State College's annual summer Arts Festival, an event that brings in more than 125,000 visitors to town every year, members staffed multiple science demonstration booths to generate excitement about STEM fields.

Many other MRSECs present activities at community events and science fairs and engage with students at local public schools to reach a wide, diverse audience. Faculty and student members of the University of Wisconsin-Madison (UW Madison) MRSEC created tabletop activities and digital education games to engage curious minds, said Anne Lynn Gillian-Daniel, Director of the Integrated Education Group at the Wisconsin MRSEC. They also organized field trips to bring local school students to campus laboratories for handson learning in a research environment. They have gone a step further to reach economically disadvantaged members of the community: the center's staff members also conduct engaging science activities at a local food pantry for kids and adults while they wait to receive service.

The 40 faculty members involved in the Wisconsin MRSEC include some from other academic institutions, such as Beloit College, The University of New Mexico, and the University of Puerto Rico at Mayagüez. Many MRSECs run a Research Experience for Undergraduates (REU) program to provide research opportunities at materials research laboratories during the summer. "Our REU is primarily focused on underrepresented minority students," said Gillian-Daniel, who, as past chair of the MRS Broadening Participation in Materials Subcommittee, oversaw its merger with the Women in Materials Science and Engineering Subcommittee and has organized workshops on mentoring and science communications at past MRS meetings.

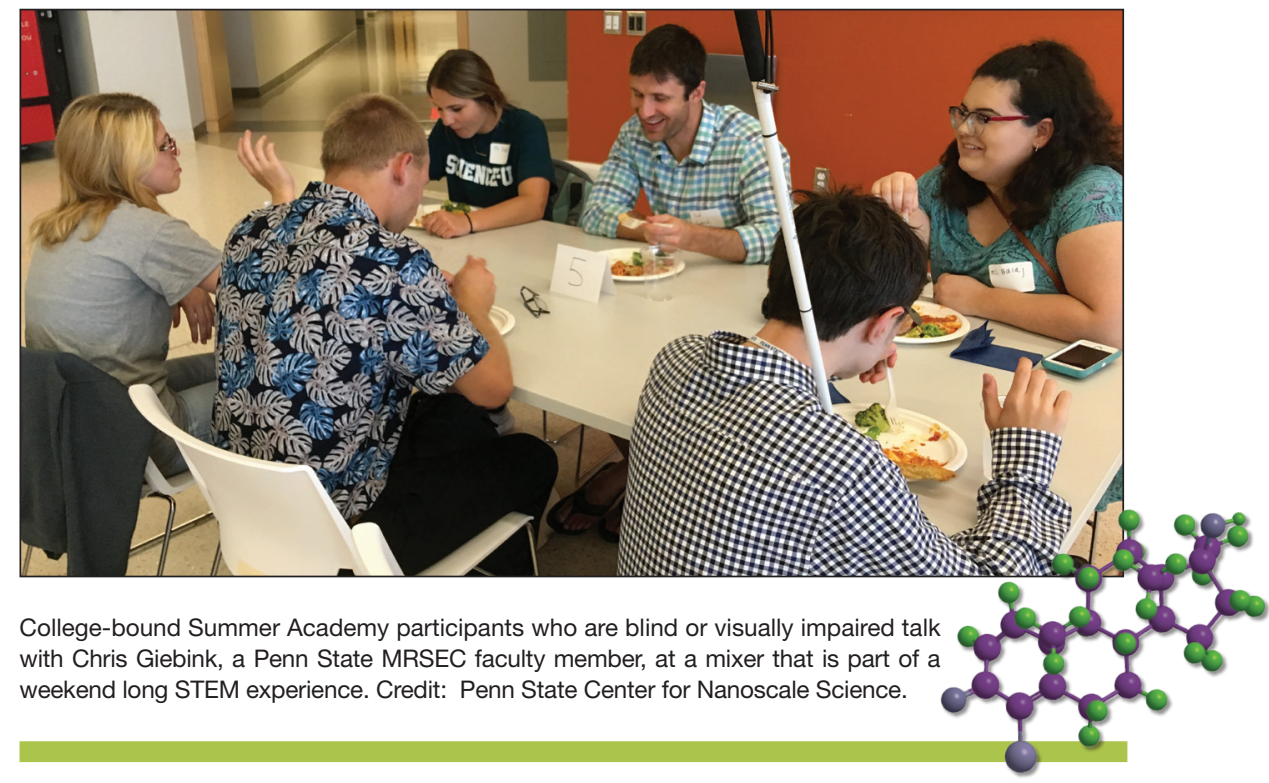

UW Madison and the University of Puerto Rico at Mayagüez have also collaborated to create a Research Experience for Teachers program. The professional development program gives middle- and high-school teachers from Wisconsin and Puerto Rico a chance to perform cuttingedge research at faculty laboratories while developing an activity that they can run in their classrooms. At the end of the summer, the teachers meet in person to share their experiences. "The teachers also take education field trips to learn about educational systems in a very different cultural environment than where they teach," said Gillian-Daniel. "It is really unique in its cross-cultural aspect."

The Brandeis University Bioinspired Soft Materials Center is one of the smallest MRSECs, said Anique OlivierMason, Director of Education, Outreach and Diversity at the center. "We try to leverage what we've got, and we integrate diversity and outreach into one program." While they conduct several outreach activities, "there are two programs we are most excited about," she said. One is the Science Communication Laboratory, or SciComm Lab, an online resource center that helps to connect graduate students and faculty members with a trained peer mentor who can offer guidance on presentations, practice talks, brainstorm ideas, or help finesse communication skills. "A significant societal problem is that many scientists lack the necessary science communication skills for their research to be understood," said Olivier-Mason. "Acquiring these skills is a challenge, because the form and content of the communication varies according to the intended audience, which could be a funding agency, a prospective employer, an outreach event, or a scientific talk."

The other, SciLinkR, is a national online platform to help promote interactions among scientists, engineers, and the public, that Olivier-Mason and her colleagues were able to set up in only six months since receiving funding in August 2018. "Whether it's teachers looking for a scientist to speak to their classes, scientists with grants seeking to perform outreach to communities, or journalists looking for experts on specific scientific topics, they can all use SciLinkR to connect," she said. "We recognize there is a hunger to connect, but there's fear or hesitance."

At the Princeton Center for Complex Materials (PCCM), in addition to the REU program, summer also brings with it the Princeton University Materials Academy, a three-week-long course for underrepresented minority students from high schools in nearby Trenton, N.J., to boost their chances of success, graduating from high school, and securing college placement. "One hundred percent of the students who have gone through the program have graduated," said Daniel Steinberg, Director of Education Outreach at PCCM, which brings 
